\title{
Examination of causes and Effects of Anxiety on Secondary School Students' Poor Academic Performance in Mathematics
}

\section{SULE, Samuel Sardauna ${ }^{1}$}

Department of Education, Faculty of Arts \& Education

\begin{abstract}
The purpose of the study was to examine the causes of anxiety on secondary school students' academic performance in mathematics in Karu Local government Area of Nasarawa State, Nigeria. It is incontrovertible that mathematics is seen as difficult subject and as a situation that makes individual appears stupid and dumb. Parents, teachers and some significant people are attributing factor to this ugly experience. But sometimes, they indicate that mathematics skills are very significant for future success. Survey research design was employed for the study. In order to provide a focus in the study, two research questions were stated. Students questionnaire was used to collect the data from the sampled of one hundred and eighty students (180). Simple percentage analysis was used to determine the percentage response. The result of analysis revealed that student's poor performance in mathematics is militated by anxiety. It also revealed that the students' anxiety in mathematics was caused by mathematics teachers, parents, boredom and learning difficulty, society, lack of adequate resources, test and examination, lack of confidence towards mathematics, altogether with students themselves. Therefore, some recommendations for possible solution were made.
\end{abstract}

Submitted

26.06.2016

Accepted

30.04.2017

Keywords:

Anxiety, Secondary

School Students,

Performance,

Mathematics

\section{Suggested Citation:}

SULE, S.S. (2017). Examination of causes and Effects of Anxiety on Secondary School Students' Poor Academic Performance in Mathematics, International Journal of Academic Research in Education, 3(1), 01-06. DOI: 10.17985/ijare.398823

\footnotetext{
${ }^{1}$ Yobe State University, Damaturu,, Nigeria E-mail: Profsam8@gmail.com Phone No: +243-706-189-3719
} 


\section{Introduction}

The mysteries of nature cannot be thoroughly understood without some knowledge of mathematics. Recent development in mathematics has shown that its knowledge penetrates into the remote areas of humanities. Despite the numerous important, mathematics and mathematics education are in a "sorry state" in Nigeria. Mathematics ever remains to suffer rejection by student of every level of education in Nigeria. This is attributed to students feeling and believes that this is very difficult and somehow reserve for exceptional students.

Ironically, mathematics never seized to be one of the compulsory subjects at the nursery, primary and secondary school level in Nigeria. Ideally, mathematics ought not to experience the negative attitude student exhibit toward it because the subject is indispensable in the scientific and technological advancement which our nation is committed to. In recent times, students achievements in mathematics examinations are poor at all level of education in this country, and are falling day in day out. The Nigerian National Concerted of 21st February, 1986 pointed out that "the 1985 "0" level exam result in mathematics, other related science subject was worst result in history". And improvement has not been experienced since then. If our nation must advance in all spheres of affairs, the causes and effects of anxiety in mathematics need to be discovered and addressed.

Anxiety is stress, tension and strain brought into one's body and mind. It can be of two types- somatic that involves the loss of control of the body, having sweating palms, pain in the neck or stick to the stomach, which involves loss of concentration, having negative self- talk, feelings of doubt or mind wonders from test (Noting, 2006). Hurlock (1972) defined anxiety as a painful uneasiness of mind concerning impending or anticipated ills. It is marked by apprehension, uneasiness and apprehension from which, the individual cannot escape. It is accompanied by feeling of helplessness because the anxious person feels blocked, unable to find a solution to his problem. An individual to borrow from future problems and therefore, suffers the present fear.

Tobias (1993) defines mathematics anxiety as feelings of tension and anxiety that interfere with the manipulation of numbers and the solving of mathematical problems in a wide variety of ordinary life and academic situations and can cause one to forget and loose one's self-confidence. Test-anxiety is a learned behavior, which can be unlearned. Some things that can create test anxiety are: parents, friends or teachers that may pass their bias to the student to make them believe that there is a connection between grade self-worth, fear of alienating parents, family or friends due to poor grades, anxiety that may be due to not feeling that are not control. The cognitive theory of test anxiety (Meichenbau and Butler, 1980; Sarason, 1975; Umoinyang, 1999; Wine, 1980) has three common components that are very important to consider in a study like this. The first is that high level of test anxiety is believed to diversely influence students' self- appraisals of evaluative situation. Secondly, test anxious students are prone to engage in more negative thoughts during evaluative tasks. Thirdly, students' performance attributions are believed to be influenced by high levels of test anxiety.

Bamidele (2005) in his study mathematics not dreadful subject stated that in Nigerian schools, students' general impression is that mathematics is dreadful subject but ironically, this subject is the basis for scientific and technological advancement of any country. This was corroborated by Prof. Samuel Ale that the subject is rather an interesting one hence, the establishment of the National Mathematical Centre (NMC) in Abuja, Nigeria. The main objectives of the (NMC) was to improve on the teaching and learning of mathematics; to develop interest in the mathematical sciences; to enable researchers in the mathematical sciences to come together for more advanced work by organizing workshops not only for Nigeria, but also for West Africa and the world at large.

Mathematics anxiety was defined as the level of discomfort that occurs among students in response to situations involving mathematical tasks, which is seen as a threat to their self- ability (Trujillo and Hadfield, 1999). It is described as a construct that involves cognitive and affective behaviors. This construct is related to personality type, negative attitudes toward mathematics, math avoidance, math background, teaching behavior, achievement levels, lack of confidence and negative experiences in school (Harper and Daane, 1998; Hembree, 1990; Sloan et al., 2002).

Arem (2009) defines mathematics anxiety as an emotional, mental and physical act related to the mathematical thinking and problem-solving process and resulting from uncomfortable past experiences as related to mathematics. Feelings and experiences like this will further affect a student's ability to learn mathematics. Based on the study, students who have experienced disappointment will have difficulty believing in their abilities in the future.

Serious harm which may lead to a significant fall in education will be done if anxiety situation is not quickly addressed after detection. This belief is the motivation towards this study. 


\section{Purpose of the Study}

This study aimed at examining the causes and effects of anxiety on secondary school students' performance in mathematics with special consideration to some selected schools. The study is meant to achieve the following specific objectives:

(i) Probe into the level of involvement of teachers, parents, learning materials /resources and the student themselves, with the view to finding solution to the problem that motivated this research.

(ii) What are the possible problems responsible for present poor performance in mathematics?

\section{Research Questions}

The following questions were stated and answered in the study:

(i) To what extent is students' mathematics performance effective in mathematics?

(ii) What are the possible problems responsible for present poor performance in mathematics?

Significance of the Study

This study is significant as it will:

(i) Go a long way to suggesting ways through in which mathematics teachers can curb the menace of anxiety in students.

(ii) Equally be an eye opener to teachers to see that the less privilege students (average students) and gifted ones can attain the same level of success as far as mathematics is concerned

(iii) Serve national interest and make parents or teachers aware of their high expectation placed on their children or students to identify the role they have to play in helping their children or students to perform well in mathematics.

Research Design

Methodology

The design of the study is a survey type. This is because the sample was gotten through random selection in order to produce a reliable result, while the population considered is a constituent of heterogeneous students.

Instrument for Data Collection

The instrument used was made up of one type of questionnaire drawn up by the researcher, which was designed to attract yes or no answer meant for the mathematics students in senior secondary school (SSS) class to measure the degree of their interest in mathematics and major problems that lead to anxiety in them. The instrument was subjected to face content validity by two science educators and three mathematics teachers. They recommended that the questions were capable of capturing the required data for the research.

\section{Sample and Sampling Technique}

The sample of this study was made up of one hundred and eighty (180) students of both sexes drawn from ten (10) selected schools using "hat and draw" random sampling technique .Eighteen (18) students made up of nine (9) boys and nine (9) girls were sampled from each school for the purpose of this research. The ten (10) sampled schools have the total of two thousand nine hundred and fifty six (2956) senior secondary students.

\section{Data Collection Techniques}

The researcher administered the questionnaires face-face with the students. The researcher instructed them to respond to the questions immediately after which he waited and collected the result at the spot.

\section{Data Analysis}

Data gathered were analyzed based on the research questions. The analysis procedure included percentage and absolute number in relation to over all sampled population.

\section{Findings}

The results of data analysis were presented based on the research questions as tabulated below: Research Question 1: To what extent is students' performance effective in mathematics? 
Table 1: Identified Items for Students' effective Performance

\begin{tabular}{|c|c|c|c|c|}
\hline $\mathbf{S} / \mathbf{N}$. & Identified Item & Response & Freq & $\%$ \\
\hline \multirow[t]{2}{*}{1.} & Always mathematics anxious & Yes & 112 & 62 \\
\hline & & No & 68 & 37.7 \\
\hline \multirow[t]{2}{*}{2.} & Maths teachers always correct & Yes & 97 & 53.9 \\
\hline & errors made & No & 83 & 46.1 \\
\hline \multirow[t]{2}{*}{3} & Maths teachers are concerned with my & Yes & 124 & 68.8 \\
\hline & Performance in mathematics & No & 56.0 & 31.1 \\
\hline \multirow[t]{2}{*}{4} & Boredom and learning difficulty & Yes & 107 & 59.4 \\
\hline & causes anxiety in me & No & 73.0 & 40.5 \\
\hline \multirow[t]{2}{*}{5} & F eel discourage with low marks in maths & Yes & 175 & 97.2 \\
\hline & test & No & 5.0 & 2.8 \\
\hline \multirow[t]{2}{*}{6} & Teaching aids enhances understanding of & Yes & 162 & 90.0 \\
\hline & my maths lesson & No & 18.0 & 10.0 \\
\hline \multirow[t]{2}{*}{7} & arents do not like maths so I see nothing & Yes & 43.0 & 23.8 \\
\hline & ood in it. & No & 137 & 76.2 \\
\hline
\end{tabular}

The table 1 showed that $62.2 \%$ students indicated that they are always anxious about mathematics. The result of students' questionnaire shows that ninety seven (97) out of the one hundred and eighty students whose percentage is (53.8) were in agreement with the facts that teachers always try their possible best to correct every error or mistake made by students. While those who were not in support was gotten to be eighty three (83) out of one hundred and eighty students and their percentage is (46.1). $43.8 \%$ respondents are of the opinion that mathematics should be better taught in the laboratory than usual classroom teaching, while $56.1 \%$ disagreed.

On teachers concern for students performance, one hundred and twenty four (124) students with 68.8\% agreed that mathematics teachers are concerned with their performance while (56) students out of one hundreds and eighty with $31.1 \%$ disagreed that mathematics teachers have concern for their performance in mathematics.

On boredom and learning difficulties as causes of students' anxiety one hundred and seven (107) which forms 59.4\% of student are on the side that boredom creates fear of mathematics in them, those with contrary view on the matter numbered seventy three (73) which becomes an obvious reflection of $40.5 \%$ of them.

It is not unusual to hear the mathematics anxious students say "I am always scared whenever information about mathematics test or examination gets to me". as indicated by information obtained from students questionnaire 175 student which is $97.2 \%$ of them feel discouraged when they obtain poor result in mathematics while only five (5) which is $2.7 \%$ of them try to resist such fear and discouragement

In addition, one hundred and sixty two (162) which is $90 \%$ of the support of the use of teaching aids during mathematics lesson. Whereas eighteen (18) representing $10 \%$ of the students feel using teaching aids confuses them thereby causing anxiety in them.

Also 43 students who formed $23.8 \%$ indicated that their parents have no interest in mathematics so they (students) also do whereas one hundred and thirty seven (137) students were not in support of the view that their parents do not like mathematics

Research Question Two: What are the possible problems responsible for present poor performance in mathematics? 
Table 2: Identified problems for Poor Academic Performance in Mathematics.

\begin{tabular}{lllcc}
\hline S/No Identified Items & Response & Frequency & Percentage (\%) \\
\hline 1 & lack of teaching aids & Yes & 120 & 66.7 \\
& & No & 60 & 33.3 \\
2 & Society inability to provide & Yes & 140 & 77.8 \\
& adequate support to students & No & 40 & 22.2 \\
3 & Lack of confidence towards & Yes & 100 & 55.6 \\
& Mathematics & No & 80 & 44.4 \\
4 & Student's lack of interest & Yes & 155 & 86.1 \\
& & No & 25 & 13.9 \\
\hline
\end{tabular}

Table 2 shows that $66.7 \%$ responded that there are lack of teaching aids or inadequate resources in their schools. And $77.8 \%$ indicated that society does not provide adequate support/help to students. Similarly, $55.6 \%$ respondents are of the opinion that lack of confidence towards mathematics stands as a cause to poor achievement. While $86.1 \%$ agreed that the student's lack of interest is also one of the causes or problems of poor achievement in mathematics.

\section{Discussion}

From the findings of the first research question, mathematics is not well taught in the laboratory than the usual classroom teaching. This may lead to students ineffective in mathematics performance It was discovered that some students lack confidence to submit their assignment to their teachers for marking. The findings of the second research question sought to identify the problems of poor achievement in mathematics. The findings indicated that many causes with the onus of ineffective or poor performance. $77.7 \%$ respondents indicated that society does not provide adequate support to students in the school and therefore not motivated towards mathematics learning. Again, one of the major causes was lack of teaching aids for the teachers to make use of in order to make mathematics learning interesting, and as a result of that, lack of teaching aids contributed to the causes of poor achievement in mathematics. This lack of teaching aids demoralized the efforts of teachers in educational sector as a whole.

Based on the research questions which try to find out whether or not anxiety generally has effect on students' performance in mathematics. It has been verified from the statistics evidence available in this study that anxiety is related to performance.

\section{Summary of the Findings}

Based on analysis of the data, the following findings were obtained:

(i) Insufficiency of resources materials is a contributing factor to the learning difficulty and sense of rejection developed against mathematics by students and that causes poor performance in mathematics.

((ii) Mathematics anxiety is instilled into a child by negligent attitude exhibited by parents and society about mathematics as the child performs in it.

(iii) Test and examination are as well discovered to be the causes of student's anxiety in mathematics. The feeling of success or failure in exam or test makes students to become anxious about their eventual performance after each examination written this lead to anxiety in mathematics.

Recommendations

Reflecting to the findings in this study, the following recommendations have been made:

(i) The teachers should as matter of necessity consider the development of positive attitude in their students in order to sustain their student's interest thereby enhancing smooth and active learning in mathematics.

(ii) Parents should understand that they have a lot to do to the development of positive attitude for mathematics in their children. In addition to teaching their children to love mathematics, parents should support their children education by regular and prompt payment of school fees and purchase the required texts books whenever necessary.

(iii) The relevant resources for learning should be provided to every school for effective learning in mathematics and enhancements of good quality of teaching.

\section{Conclusion}

So far the paper has reported a study conducted into the causes and effects of anxiety in students' achievement in mathematics on senior secondary school (SSS) students. 
This study revealed that there were insufficient learning materials (teaching aids) in the majority of the secondary schools in the area of study. It was discovered that higher number of students were always anxious about tests and examinations results and parents gives no helping hand in motivating students to learn mathematics.

Thus, this study has implications for both teachers, students, parents, and society by encouraging those with a vested interest in the success of their students to take into account mathematics anxiety levels before determining effective and appropriate strategies when teaching and learning is carried out. As such, it is believed that the causes of anxiety and poor performance in mathematics can be reduced.

Arem, C.A. (2009). Conquering Math Anxiety. 3rd Edn., Cengage Learning, Belmont, ISBN-10:0495829404, 215.

Bamidele, R. (2005). Mathematics not a dreadful Subject. Daily Sun. Aug, 30: 22-25.

Hurlock. E.N. (1972). Child Development 5th Edn., Hill Book Co., New York.

Hembree, R. (1990). The nature, effects and relief of mathematics anxiety. J. Res. Math.Educ., 22: 33-46.

Meichenbau, D. and Butler, L. (1980). Towards a Conceptual Model for the Treatment of Test Anxiety: Implication for Research and Treatment. In: Test-Anxiety, Theory, Research and Applications,Sarason, I.G.Ed.).Erlbaum, Hillsdale, New Jersey, 187-385.

Paul, D. and Nolting. P.D. (2006). Wining at Math. Your Guide to learning Mathematics

Through Successful Study Skills. Academic Success Press, Bradenton, FL, 356

Sarason, I.G. (1975). Test Anxiety, Attention and the General Problem of Anxiety. In Stress and Anxiety 11, Spielberder, C.D. and I.G Sarason (Eds.).Hemisphere Gold Inc., Washington, DC.,165-188.

Trujillo, K.M. and Hadfield, O.D. (1999). Tracing the roots of mathematics anxiety through in Depth interviews with preservice elementary teachers. College Student J.33: 219.

Tobias, S. (1993). Overcoming Mathematics Anxiety.W.W. Norton and Co., New York.

Umoinyang, I E. (1999). Student Socio-psychological factors as determinants of achievement in Senior secondary school mathematics, Ph.D. Thesis, University of Ibadan, Ibadan. 